\title{
Impact of Covid-19 Pandemic on Mental State, Personal Finance and the Economy: Evidence from the United States
}

\author{
Titilope Akinsanmi $^{1} \quad$ Abisoluwa Akinboboye $^{2} \quad$ Chukwuemeka Ebiringa $^{3}$ \\ 1.Department of Public Policy \& Urban Affairs, Southern University and A \& M College, Baton Rouge, \\ Louisiana \\ 2.Department of Brand and Media Strategy, East Tennessee State University, Johnson City, Tennessee \\ 3.Department of Clinical Mental Health Cancelling, Southern University and A \& M College, Baton Rouge, \\ Louisiana
}

\begin{abstract}
This paper investigated the impact of COVID-19 pandemic on the mental state of the US residents, as well as the impact of mental state on personal finance and the US economy. The objectives of the current study were to: (i) determine the factors affecting the psychological state of US residents following COVID-19 outbreak; (ii) evaluate the impact of mental state and personal life on economy and finance. By deploying quantitative research design, secondary survey data relating to the US were analysed using descriptive statistics and structural equation modelling. Result shows that a sizable proportion of people are worried about their mental health because of the COVID-19. Furthermore, the level of satisfaction with the national government's response to the COVID-19/ coronavirus pandemic in the United States is low, while people are generally not satisfied with fellow citizens' response to the COVID-19 / coronavirus pandemic in the United States. However, the level of Satisfaction with hospitals' response to the COVID-19 / coronavirus pandemic in the United States is generally high. The two factors affecting the psychological state of US residents are the impact of the COVID-19 / coronavirus pandemic on personal finances and the level of hospitals' response to the COVID-19 (research objective one). Worry and mental state both affect people's everyday life, however, the impact of worry is more pronounced on everyday life, as this may affect people's productivity (research objective two). Considering that US residents/ citizens are generally satisfied with the measures taken by hospitals to tackle the spread of COVID-19 and treat COVID-19 pandemic, the study recommends that more public funds should be pledged to upscaling the quality and capacity of health infrastructure in the US. This becomes important considering that hospitals have a great impact on the psychological state of residents.
\end{abstract}

Keywords: COVID-19, mental health, personal finance, US economy, social distancing

DOI: $10.7176 / \mathrm{JESD} / 12-6-09$

Publication date:March $31^{\text {st }} 2021$

\section{INTRODUCTION}

The COVID-19 global pandemic has undoubtedly affected the nations of the world (Thelwall \& Thelwall, 2020). Considering that in the wake of the COVID 19 outbreak, people had to grapple with fear, loneliness, panic, anxiety, and separation from loved ones in order to cope with the ravaging effect of the pandemic (Mahmoud-Saleh \& Karia, 2020). As observed from the literature, there is an undeniable fact that the global pandemic has altered peoples' way of lives (Frimpong, 2020). As a result, several public health protocols were introduced by the Wealth Health Organization including hand-washing, use of sanitizers, wearing of masks and social distancing to contain the spread of the COVID-19 virus. By dwelling on the significant role of social distancing, as a nonpharmacological intervention strategy to contain the spread of the virus (Nagel, 2020), maintaining social distance is now a 'new normal' affecting several people in different dimensions, especially the vulnerable. This also affects those experiencing cognitive decline such as elderly people, people suffering from drug and alcohol use, and those suffering from dementia and Alzheimer's disease, among others (Emerson, 2020; Omobowale, Oyelade, Omobowale \& Falase, 2020). As the psychological state of people's mind may affect their productivity and contribution to economic development, it is important to provide empirical evidence on the nexus between Mental state of mind, personal finance and the economy.

As self-isolation and social distance are now ubiquitous practice embraced as the new trend-which is unlikely to go away anytime soon - it becomes important to investigate the impact of social isolation on personal finance, and its associated effect on the larger economy (The New York Times, 2020). Meanwhile, knowledge on the impact of mental state and social isolation on the people's finance and the economy will be helpful to organisations and governments of the world in formulating post-COVID-19 policies that may actualise the achievement of UN SDG 3 (Good Health \& Well-Being) in the light of the recent global health pandemic. The study focused on the United States of America (US). US is among the countries with the highest infection rate and COVID-19 death tolls. Other countries such as Italy, Spain, France and UK are among the top-ranking nations with high spate of COVID-19 infection and number of deaths. As of April 23, 2020, the number of COVID-19 induced deaths stood at 47,681, followed by Italy with death toll of 25,085 and Spain recording 21,717 deaths at 
the time (World Health Organization, 2020). Therefore, a study from the US is both timely and relevant considering that the country has the highest infection rate of COVID-19 in the world. An exposition on how COVID-19 has affected peoples' personal lives and finance, and the US economy is very critical for formulation of post-COVID-19 recovery policy in the US. Given the economic and political power of the US among nations of the world, the study is also relevant to other countries in formulating strategies that will see to the recovery of the world economy following the COVID-19 outbreak.

Against this backdrop, the objectives of the current study are to: (i) determine the factors affecting the psychological state of US residents following COVID-19 outbreak; (ii) evaluate the impact of mental state and personal life on economy and finance. Result shows that a sizable proportion of people are worried about their mental health because of the COVID-19. Furthermore, the level of satisfaction with the national government's response to the COVID-19 / coronavirus pandemic in the United States is low, while people are generally not satisfied with fellow citizens' response to the COVID-19 / coronavirus pandemic in the United States. However, the level of Satisfaction with hospitals' response to the COVID-19 / coronavirus pandemic in the United States is generally high. The two factors affecting the psychological state of US residents are the impact of the COVID-19 / coronavirus pandemic on personal finances and the level of hospitals' response to the COVID-19 (research objective one). Worry and mental state both affect people's everyday life, however, the impact of worry is more pronounced on everyday life, as this may affect people's productivity (research objective two). The economy of US is worse hit by COVID in comparison to people's personal finance. This may be expected because adverse effect on individual finance sums up to determine the overall impact on the entire economy.

\section{LITERATURE REVIEW OF COVID-19 OUTBREAK, MENTAL HEALTH AND THE ECONOMY}

In the wake of the COVID-19 outbreak, social isolation was supposedly one of the most prominent and effective non-pharmacological strategies for containing the spread of the highly contagious and deadly Coronavirus, as evidenced by the imposition of lockdown in many nations of the world (Hamdan-Mansour, Al Shibi, Khalifeh \& Hamdan Mansour, 2020).

However, considering that people suffering from cognitive decline heavily require the assistance of care givers and family members (Eley, 2016), there is the possibility that the absence of such requisite support may adversely affect persons in this category. Social isolation may have negative impact on patients experiencing cognitive decline (Evans \& Bray, 2016; Chapman, 2018). This may extend to memory decline and language coordination (Gethin - Jones, 2012; Dayrit \& Mendoza, 2020). Studies show that absence of human interaction or contact is associated with decline in cognitive function (Offord, 2020; Guido, Pichierri, Rizzo, Chieffi \& Moschis, 2020). Relatedly, psychology and learning theories suggest that human beings are both psychological and social beings (Boddy, 2012; Mullins \& Christy, 2013). Few personal relationships by people undergoing psychological therapy on substance abuse may reverse the gains of recovery and may even worsen the condition of patients through reinforced consumption of narcotic drug or increased use of harmful substance (Burke \& Cocoman, 2020). The increased consumption of harmful substance as a result of lack of communication to the outside world by people suffering from the direct and remote effects of substance abuse threatens their health, safety and overall wellbeing (World Health Organisation, WHO 2002, 2012).

Whereas there is a body of literature suggesting that social isolation may aggravate mental health disorders and could negatively affect social and emotional wellbeing of people, the debate is inconclusive as result from empirical studies is mixed (e.g. Oliver, Murphy \& Cox, 2010; Gethin-Jones, 2014). Although there appears to be evidence that social isolation may contribute to cognitive decline in older people (e.g. Burke \& Cocoman, 2020; Offord, 2020), empirical evidence to support this proposition is lacking. Literature suggests that questions surrounding the potential detrimental effects of social isolation occasioned by pandemic or other circumstances on older adults remain unaddressed (e.g. Manca, De Marco \& Venneri, 2020; Vindegaard \& Benros, 2020). Further, empirical evidence on the link between social isolation, cognition and language behaviour is still sparse (e.g., Gethin - Jones, 2012; Düzel \& Drewelies, 2019; Vindegaard \& Benros, 2020), as it appears the subject is underresearched. Some scholars argue that cognition decline on account of little communication with the outside world is not peculiar to the older people, but equally affects people not suffering any cognitive dysfunction. Other studies suggest that the effective deployment of information technology can overcome some problems occasioned by lack of one-on-one contact during social isolation (e.g. Nagel, 2020; Singh, Singh, Houssein \& Ahmad, 2020).

Whilst there is growing evidence that social isolation may have negative impact on mental wellbeing of older people and persons with cognitive impairments, other studies have punctured this claim by presenting evidence that reduction or withdrawal of assistance may have no significant adverse effect on this set of vulnerable people in the society. In reconciling the diverging views of scholars, it appears limited sample size and scope in most studies is affecting generalisability of results. Most studies on the subject have used one data-collection technique of either structured questionnaire (e.g. Emerson, 2020; Shrira, Hoffman, Bodner \& Palgi, 2020), interview (e,g. Lara, Carnes, Dakterzada, Benitez \& Piñol-Ripoll, 2020), case study (e.g. Fahed, Barron \& Steffens, 2020; Hwang, Kim, Park, Chang \& Park, 2020), or analysis of archival data (e.g. Padala, Jendro \& Orr, 2020). The use of one- 
sided data-collection technique, and the ensuing data-analysis technique, in many studies may be contributory to the lack of consensus among scholars on the impact of social isolation on patients experiencing cognitive decline. Decline in cognition affects the metal state of people, and this may affect their ability to contribute meaningfully to national economic development. Decline in personal finance on account of reduced mental cognition may negatively affect the economy at large, since it is individual contribution to the economy that is aggregated to determine the world economy.

Although there appears to be evidence that social isolation may contribute to cognitive decline in older people and persons with cognitive impairments, empirical evidence to support this proposition is lacking, as results reported in literature are contradictory. The use of a data triangulation strategy such as combining primary datacollection (questionnaire and interview) with archival data may improve the quality of research findings. Larger and more robust research designs are required to provide well-validated findings. This study attempts to close this gap by empirically examining the link between mental state, personal finance and economic development in the US.

\section{METHODOLOGY}

\subsection{Research Design and Measurement of Variables}

Quantitative research design was adopted for the study using the survey method. Survey research design was selected because it affords the researcher the opportunity to gather quantitative data conveniently and economically from large number of respondents (Ghauri \& Grønhaug, 2005). However secondary survey data was used covering the country under focus. The variables of the study and how they were measured is presented in Table 2.

Table 1: Measurement of Variables

\begin{tabular}{|l|l|l|}
\hline S/N & $\begin{array}{l}\text { Variable } \\
\text { Name }\end{array}$ & Measurement and Connotation \\
\hline 1 & Economy & $\begin{array}{l}\text { economic stability as a result of the COVID-19 / coronavirus pandemic in the } \\
\text { United States, United Kingdom, Germany and China 2020 }\end{array}$ \\
\hline 2 & Life & $\begin{array}{l}\text { Level of impact of the COVID-19 / coronavirus pandemic on people's everyday } \\
\text { life in the United States, United Kingdom, Germany and China 2020: } \\
\text { SCALE 1 (No impact at all) to 10 (severely impacted) }\end{array}$ \\
\hline 3 & Mental & $\begin{array}{l}\text { Share of persons worried about their mental health because of the COVID-19 / } \\
\text { coronavirus pandemic in the United States, United Kingdom, Germany and China } \\
\text { 2020 }\end{array}$ \\
\hline 4 & Worry & $\begin{array}{l}\text { Share of persons most worried about the COVID-19 / coronavirus pandemic in the } \\
\text { United States, United Kingdom, Germany and China }\end{array}$ \\
\hline 5 & Govt. & $\begin{array}{l}\text { Satisfaction with the national government's response to the COVID-19 } \\
\text { coronavirus pandemic in the United States, United Kingdom and Germany 2020 }\end{array}$ \\
\hline 7 & Finance & $\begin{array}{l}\text { Level of impact of the COVID-19 / coronavirus pandemic on people's personal } \\
\text { finances in the United States, United Kingdom, Germany and China 2020. } \\
\text { SCALE 1 (No impact at all) to10 (severely impacted) }\end{array}$ \\
\hline 8 & Hospital & $\begin{array}{l}\text { Satisfaction with fellow citizens' response to the COVID-19 / coronavirus } \\
\text { pandemic in the United States, United Kingdom, Germany and China 2020 }\end{array}$ \\
\hline $\begin{array}{l}\text { Satisfaction with hospitals' response to the COVID-19 / coronavirus pandemic in } \\
\text { the United States, United Kingdom and Germany 2020 }\end{array}$ \\
\hline
\end{tabular}

Source: Author's Modification

\subsection{Method of Data Collection}

Survey Data on the COVID 19 pandemic covering the four countries under consideration were obtained from the database of statistica (https://statistica.com). The data covered the eight variables enumerated in Table 1 for the four countries for 30-daily observations, making a total of 960 observations used in the analysis. The survey spanned across two months (March to April 2020) when the COVID-19 cases peaked all over the world. The use of survey data covering this period is adjudged appropriate considering that this was the peak period when the government of nations started restricting movement, imposing curfews and invoking lockdown as measures to contain the spread of the virus. Thus, survey data generated this period is considered to be a reflection of the severity of the COVID-19 outbreak on social and economic system. The focus on the four countries is justified on the basis that they are part of the countries worst hit by the COVID-19 outbreak (Table 1 shows the death toll per country affected by the COVID-19 outbreak). By considering the complexity of the interrelationship between the variables, a structural equation modelling approach was used to assess the impact of the COVID-19 on these variables. Data analysis was aided by STATA 14 software. 
4. DATA PRESENTATION AND DISCUSSION

Table 2: Descriptive Statistics of study variables

\begin{tabular}{r|rrrrr} 
Variable & Obs & Mean & Std. Dev. & Min & Max \\
\hline economy & 60 & 65.86667 & 5.026933 & 51 & 74 \\
life & 60 & 7.056667 & .2235057 & 6.6 & 7.4 \\
mental & 60 & 27.8 & 4.375587 & 16 & 34 \\
worry & 60 & 60.73333 & 4.441204 & 54 & 70 \\
govt & 60 & 38.13333 & 5.067232 & 25 & 46 \\
\hline finance & 60 & 5.503333 & .3329206 & 5 & 6.2 \\
citizen & 60 & 36.06667 & 5.108539 & 25 & 45 \\
hospital & 60 & 76.93333 & 4.116386 & 69 & 85
\end{tabular}

Source: Author's Analysis (2021)

From the result in Table 2, with a Mean of 65.86/100, it appears that the US economy is noticeably shaken by the COVID pandemic. With ab average score of $7 / 10$, people's everyday life is severely impacted by the COVID outbreak in the United States. A sizable proportion of people are worried about their mental health because of the COVID-19. Furthermore, the level of satisfaction with the national government's response to the COVID-19/ coronavirus pandemic in the United States is low $(\mathrm{M}=38.13 \%)$. The severity of impact of the COVID-19/ coronavirus pandemic on people's personal finances in the United States is moderate $(\mathrm{M}=5.5 / 10)$. People are generally not satisfied with fellow citizens' response to the COVID-19 / coronavirus pandemic in the United States $(\mathrm{M}=36.06 / 100)$. However, the level of Satisfaction with hospitals' response to the COVID-19 / coronavirus pandemic in the United States is generally high $(\mathrm{M}=76.9 \%)$. Taken together, this scenario provides a good context to investigate the factors affecting the psychological state of US residents with respect to the COVID-19 pandemic.

\subsection{Factors Affecting the psychological state of US residents following COVID-19 outbreak}

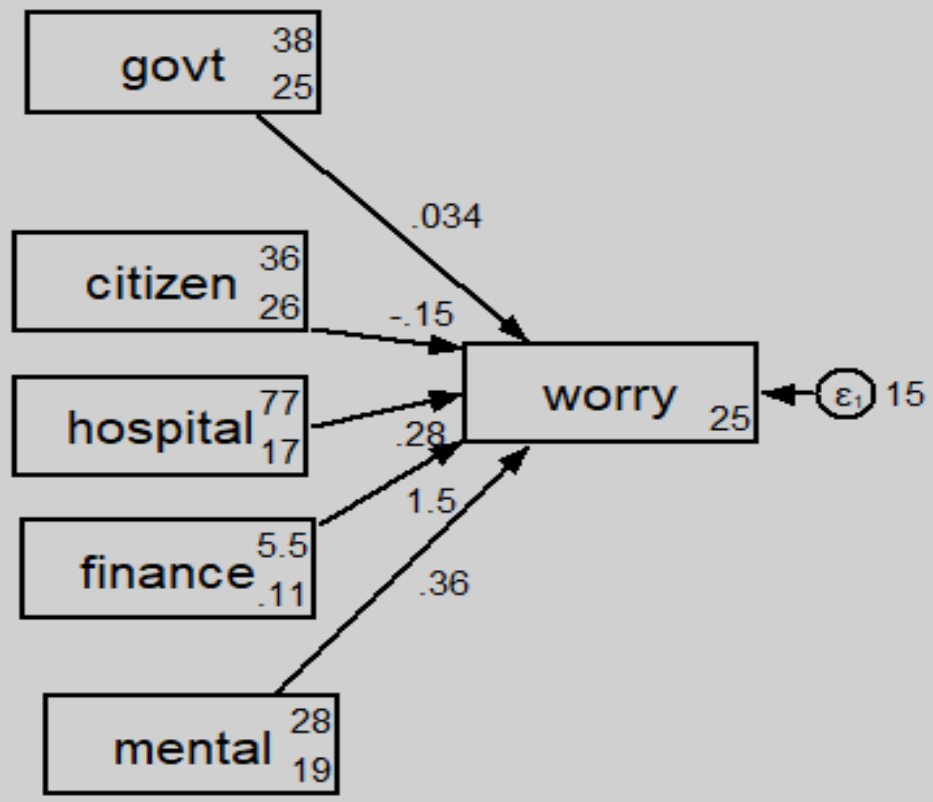

Figure 1: Determinants of the Psychological State of US Residents following COVID-19 outbreak Source: Researchers' Conceptualization (2021) 
Table 3a: Determinants of the Psychological State of US Residents following COVID-19 outbreak

\begin{tabular}{|c|c|c|c|c|c|}
\hline & OIM & & & & \\
\hline & Coefficient & Standard Error & $\mathrm{Z}$ & $\mathrm{P}>|\mathrm{z}|$ & {$[95 \%$ Conf. Interval] } \\
\hline \multicolumn{6}{|l|}{ Structural } \\
\hline \multicolumn{6}{|l|}{ worry <- } \\
\hline govt & .0337167 & 0.1124052 & 0.30 & 0.764 & $\begin{array}{ll}.1865935 & .2540269\end{array}$ \\
\hline citizen & -.1491142 & 0.1092089 & -1.37 & 0.172 & $\begin{array}{ll}.3631598 & .0649314 \\
\end{array}$ \\
\hline hospital & .277525 & 0.1274516 & 2.18 & 0.029 & $.0277244 \quad .5273256$ \\
\hline finance & 1.467428 & 1.601341 & 0.92 & 0.359 & $-1.671144 \quad 4.605999$ \\
\hline mental & .3624073 & 0.1289943 & 2.81 & 0.005 & $.1095832 \quad .6152314$ \\
\hline cons & 25.32406 & 13.73356 & 1.84 & 0.065 & $-1.593217 \quad 52.24134$ \\
\hline var(e.worry) & 14.80987 & 2.7039 & & & 10.35485 \\
\hline
\end{tabular}

Source: Author's Analysis, 2021

Table 3b: Model Fit statistics for Model 1

\begin{tabular}{|c|c|}
\hline \begin{tabular}{l|l} 
Fit statistic & \\
\end{tabular} & Value Description \\
\hline \multicolumn{2}{|l|}{ Likelihood ratio } \\
\hline chi2_ms $(0)$ & 0.000 model vs. saturated \\
\hline \multicolumn{2}{|l|}{$\mathrm{p}>\mathrm{chi} 2$} \\
\hline chi2_bs(5) & 16.185 baseline vs. saturated \\
\hline $\mathrm{p}>\mathrm{chi} 2$ & 0.006 \\
\hline \multicolumn{2}{|l|}{ Population error } \\
\hline RMSEA | & 0.000 Root mean squared error of approximation \\
\hline $90 \% \mathrm{CI}$, lower bound & 0.000 \\
\hline upper bound | & 0.000 \\
\hline pclose & 1.000 Probability RMSEA $<=0.05$ \\
\hline \multicolumn{2}{|l|}{ Information criteria } \\
\hline $\mathrm{AIC}$ & 1772.450 Akaike's information criterion \\
\hline $\mathrm{BIC}$ & 1787.110 Bayesian information criterion \\
\hline \multicolumn{2}{|l|}{ Baseline comparison } \\
\hline CFI & 1.000 Comparative fit index \\
\hline TLI & 1.000 Tucker-Lewis index \\
\hline \multicolumn{2}{|l|}{ Size of residuals } \\
\hline SRMR & 0.000 Standardized root mean squared residual \\
\hline $\mathrm{CD}$ & 0.236 Coefficient of determination \\
\hline
\end{tabular}

Source: Author's Analysis, 2021

From the result in Table 3a, the factors having the severest impact on the psychological state of US residents are impact of the COVID-19 / coronavirus pandemic on personal finances $(b=1.467428)$ and level of Satisfaction with hospitals' response to the COVID-19 $(b=.277525)$. Share of persons worried about their mental health (i.e. mental, $\mathrm{b}=.3624073$ ) emerged as a significant predictor, thus justifying its inclusion in the Model as a control variable affecting the psychological state of people. The effect size of Satisfaction with the national government's response to the COVID-19 (govt, $\mathrm{b}=.0337167$ ) and fellow citizens' response to the COVID-19 (citizen $=.1491142$ ) is negligible and not statistically significant. This suggests that govt and citizen have no impact on the psychological state of US residents/citizens. A plausible reason for the lack of statistical significance of govt is that people do not believe that the government/ government policies may not adequately curtail the spread of COVID-19. Also, citizen may be insignificant because people do not trust other people to instill adequate measures to control the spread of COVID-19. However, as US residents/ citizens are generally satisfied with the measures taken by hospitals. Hospitals have a great impact on the psychological state of residents. Result in Table $3 \mathrm{~b}$ confirms that the Model is well fitting.

In sum, the two factors affecting the psychological state of US residents are the are impact of the COVID-19 / coronavirus pandemic on personal finances and the level of hospitals' response to the COVID-19 (research 
objective one).

\subsection{Impact of Mental state and Personal life on Economy and Finance}

Result on the impact of Mental state and Personal life on Economy and Finance is presented as follows:

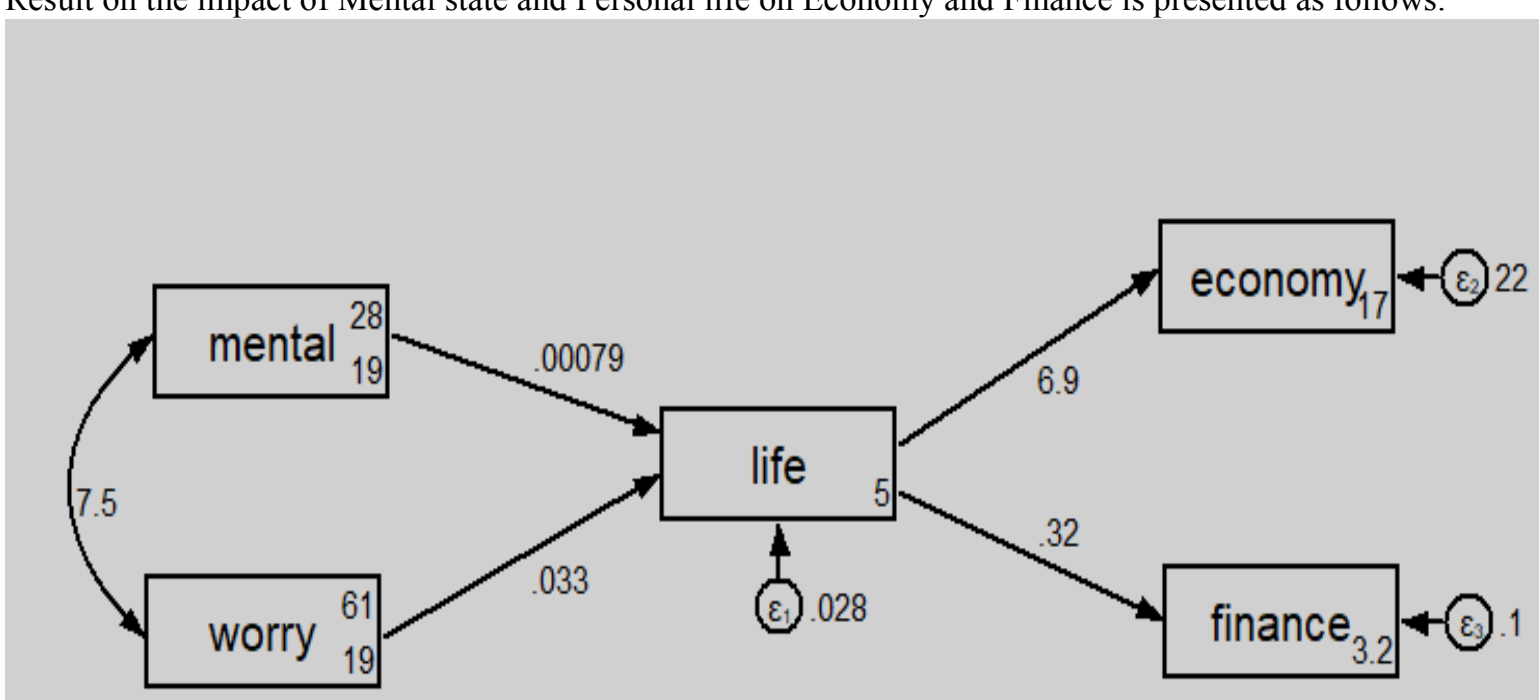

Figure 2: Impact of Mental state and Personal life on Economy and Finance Source: Researchers' Conceptualization (2021)

Table 4a: Impact of Mental state and Personal life on Economy and Finance

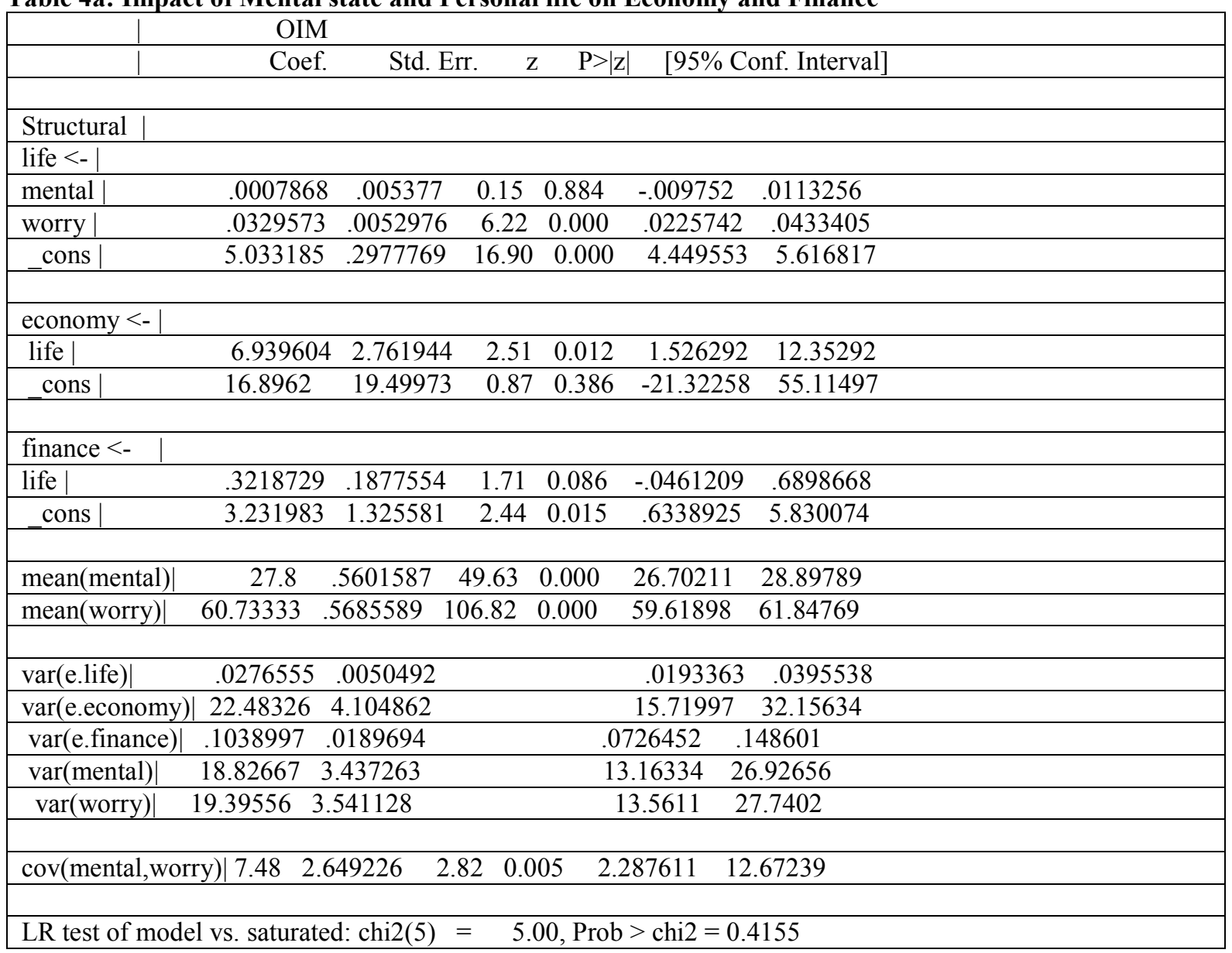

Source: Author's Analysis, 2021 
Table 4b: Model fitness

\begin{tabular}{|c|c|}
\hline Fit statistic & Value Description \\
\hline \multicolumn{2}{|l|}{ Likelihood ratio } \\
\hline chi2_ms(5) & 5.003 model vs. saturated \\
\hline $\mathrm{p}>\mathrm{chi} 2$ & 0.415 \\
\hline chi2_bs(9) & 48.344 baseline vs. saturated \\
\hline $\mathrm{p}>\mathrm{chi} 2$ & 0.000 \\
\hline \multicolumn{2}{|l|}{ Population error } \\
\hline RMSEA & 0.003 Root mean squared error of approximation \\
\hline $90 \% \mathrm{CI}$, lower bound & 0.000 \\
\hline upper bound & 0.179 \\
\hline pclose & 0.502 Probability RMSEA $<=0.05$ \\
\hline \multicolumn{2}{|l|}{ Information criteria } \\
\hline AIC & 1061.034 Akaike's information criterion \\
\hline $\mathrm{BIC} \mid$ & 1092.449 Bayesian information criterion \\
\hline \multicolumn{2}{|l|}{ Baseline comparison } \\
\hline CFI & 1.000 Comparative fit index \\
\hline TLI $\mid$ & 1.000 Tucker-Lewis index \\
\hline \multicolumn{2}{|l|}{ Size of residuals } \\
\hline SRMR | & 0.065 Standardized root mean squared residual \\
\hline $\mathrm{CD} \mid$ & 0.437 Coefficient of determination \\
\hline
\end{tabular}

Source: Author's Analysis, 2021

In Table $4 \mathrm{a}$, mental and worry are strong and statistically significant covariates $(b=7.48, p=0.005<.01)$ which implies that worry affects the mental state and vice versa. Worry and mental state both affect people's everyday life, however, the impact of worry is more pronounced on everyday life, as this may affect people's productivity.

Result shows that COVID affects people's everyday life to the extent that it affects their contribution to the economy $(b=6.939604, p<.05)$. Therefore, COVID affects economic stability as people may not be able to contribute meaningfully to economic growth and development because of their worry/mental state. Furthermore, COVID affects people's everyday life to the extent that it affects their personal finance $(b=.3218729, p<.10)$. However, the impact of COVID with respect to everyday life and personal finance is not as severe that of the entire economy. In other words, the economy of US is worse hit by COVID in comparison to people's personal finance. This may be expected because adverse effect on individual finance sum up to determine the overall impact on the entire economy.

To check the robustness of result in Table $4 \mathrm{a}$, alternative model is proposed and inestigated as presented in section 3.3 .

4.3 Alternative Model on Impact of worry on Finance (with Life, mental and Worry modelled as covariates) Result from alternative model on impact of worry on finance (with Life, mental and Worry modelled as covariates) is presented as follows: 


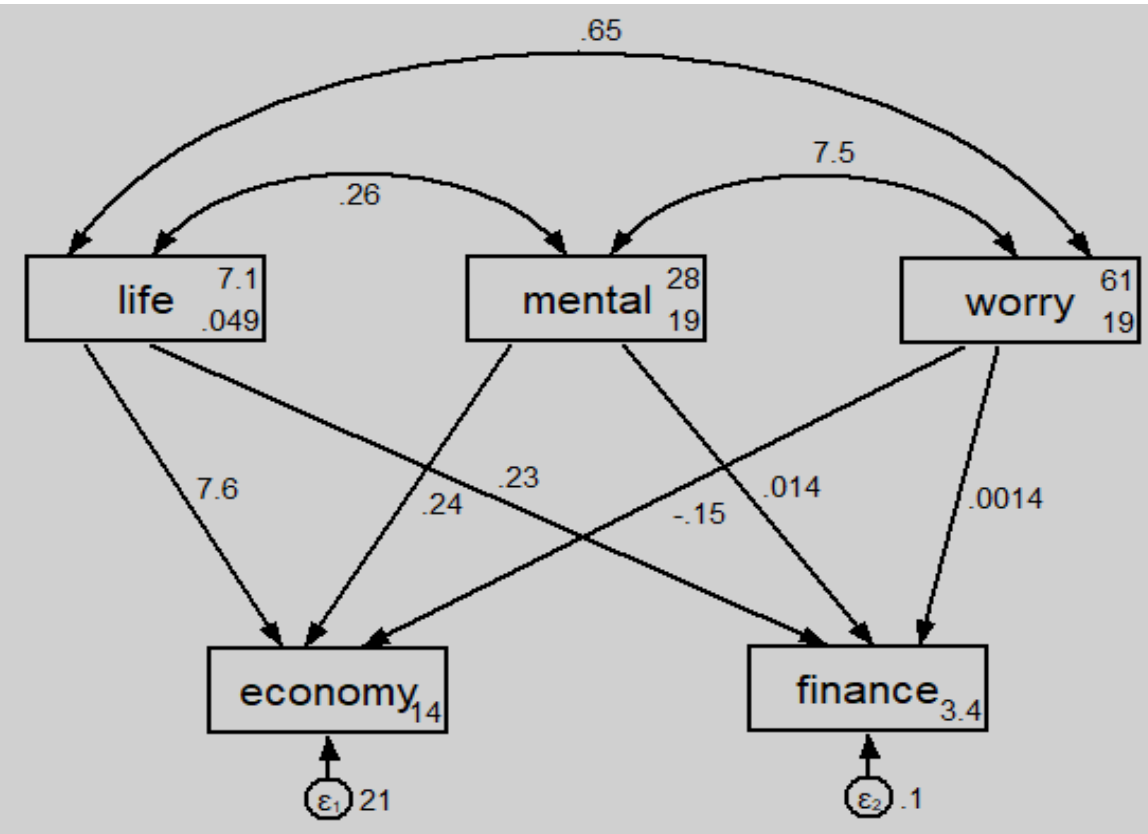

Figure 3: Alternative Model on Impact of worry on Finance (with Life, mental and Worry modelled as covariates)

Source: Researchers' Conceptualization (2021)

Table 5a: Alternative Model on Impact of worry on Finance (with Life, mental and Worry modelled as covariates)

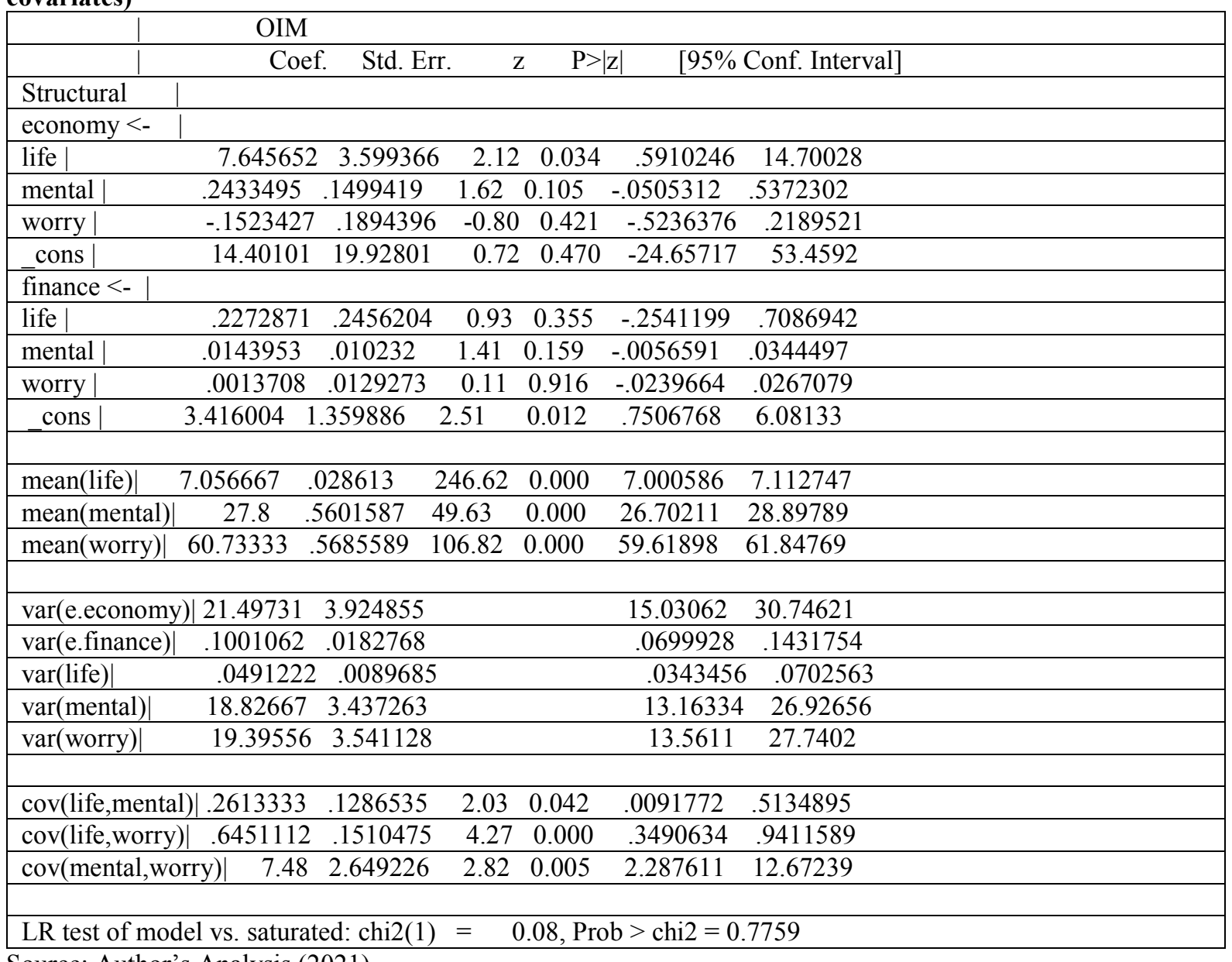

Source: Author's Analysis (2021) 
Table 5b: Model Fitness:

\begin{tabular}{|c|c|}
\hline Fit statistic & Value Description \\
\hline \multicolumn{2}{|l|}{ Likelihood ratio } \\
\hline chi2_ms(1) & 0.081 model vs. saturated \\
\hline $\mathrm{p}>\mathrm{chi} 2$ & 0.776 \\
\hline chi2 bs(7) & 13.875 baseline vs. saturated \\
\hline $\mathrm{p}>\mathrm{chi} 2$ & 0.053 \\
\hline \multicolumn{2}{|l|}{ Population error| } \\
\hline RMSEA | & 0.000 Root mean squared error of approximation \\
\hline $90 \%$ CI, lower bound & 0.000 \\
\hline upper bound $\mid$ & 0.227 \\
\hline pclose & 0.792 Probability RMSEA $<=0.05$ \\
\hline \multicolumn{2}{|l|}{ Information criteria } \\
\hline $\mathrm{AIC}$ & 1064.111 Akaike's information criterion \\
\hline $\mathrm{BIC} \mid$ & 1103.904 Bayesian information criterion \\
\hline \multicolumn{2}{|l|}{ Baseline comparison } \\
\hline CFI $\mid$ & 1.000 Comparative fit index \\
\hline TLI $\mid$ & 1.936 Tucker-Lewis index \\
\hline \multicolumn{2}{|l|}{ Size of residuals } \\
\hline SRMR | & 0.008 Standardized root mean squared residual \\
\hline $\mathrm{CD} \mid$ & 0.198 Coefficient of determination \\
\hline
\end{tabular}

Source: Author's Analysis, 2021

In the alternative model, life, mental and worry are modelled as covariates because of the linkage between being worried, the mental state and how the mental state affects one's disposition and psychological fitness to perform optimally and contribute to nation-building. Result supports that they are significant covariates as seen that life/mental $(b=.2613333, p<.05)$, life/worry $(b=.6451112, p<.05)$ and mental/worry $(b=7.48, p<.05)$. the impact of COVID-19 worry about everyday life on economic stability is significant $(b=7.645652)$. This is consistent with the result in Table 4a. Although the impact of mental and worry on economic stability appear negligible and appear to be not statistically significant, the consideration that mental and worry are significant covariates with life suggest that they indirectly affect economic stability.

The impact of COVID worry about everyday life with respect to personal finance is also notable ( $\mathrm{b}=.2272871$, $\mathrm{p}>.05$ ) but is not statistically significant. This also corroborates the result in Table 4a that the impact of COVID on personal finance is not as severe as its impact on the aggregate economy (research objective two).

\section{CONCLUSION}

This paper investigated the impact of COVID-19 pandemic on the mental state of the US residents, as well as the impact of mental state on personal finance and the US economy. The objectives of the current study were to: (i) determine the factors affecting the psychological state of US residents following COVID-19 outbreak; (ii) evaluate the impact of mental state and personal life on economy and finance. By deploying quantitative research design, secondary survey data relating to the US was used for analysis. Descriptive statistics and structural equation modelling were used to analyse data. Result shows that a sizable proportion of people are worried about their mental health because of the COVID-19. Furthermore, the level of satisfaction with the national government's response to the COVID-19 / coronavirus pandemic in the United States is low, while people are generally not satisfied with fellow citizens' response to the COVID-19 / coronavirus pandemic in the United States. However, the level of Satisfaction with hospitals' response to the COVID-19 / coronavirus pandemic in the United States is generally high. The two factors affecting the psychological state of US residents are the impact of the COVID-19 / coronavirus pandemic on personal finances and the level of hospitals' response to the COVID-19 (research objective one). Worry and mental state both affect people's everyday life, however, the impact of worry is more pronounced on everyday life, as this may affect people's productivity (research objective two). The economy of US is worse hit by COVID in comparison to people's personal finance. This may be expected because adverse effect on individual finance sum up to determine the overall impact on the entire economy. 
Considering that US residents/ citizens are generally satisfied with the measures taken by hospitals to tackle the spread of COVID-19 and treat COVID-19 pandemic, the study recommends that more public funds should be pledged to upscaling the quality and capacity of health infrastructure in the US. This becomes important considering that hospitals have a great impact on the psychological state of residents. It is also important that the government increase access to public hospital facilities that citizens/ residents can have better access to treatment and increase the chances of survival because the cost of individual treatment of COVID-19 may be high, especially in the light of declining financial capacity, since COVID-19 has adversely affected personal finance and the economy in general.

\section{REFERENCES}

Boddy, D. (2012). Essentials of management: A concise introduction. Pearson Education Limited.

Burke, D., \& Cocoman, A. (2020). Training needs analysis of nurses caring for individuals an intellectual disability and or autism spectrum disorder in a forensic service. Journal of Intellectual Disabilities and Offending Behaviour, 11(1), 9-22. https://doi.org/10.1108/JIDOB-10-2019-0024

Chapman, F. (2018). Managing emotional and psychological distress in older people. Working with Older People, 22 (4), 234-242. https://doi.org/10.1108/WWOP-09-2018-0017

Dayrit, M.M., \& Mendoza, R.U. (2020). Social cohesion vs COVID-19. International Journal of Health Governance, 25 (3),191-203. https://doi.org/10.1108/IJHG-03-2020-0022

Düzel, S., \& Drewelies, J. (2019). Structural brain correlates of loneliness among older adults. Scientific Reports, 9, 135-169. https://doi.org/10.1038/s41598-019-49888-2

Eley, R.M. (2016). Telling it as it is: involving people with dementia and family carers in policy making, service design and workforce development. Working with Older People, $20 \quad$ (4), 219222. https://doi.org/10.1108/WWOP-09-2016-0026

Emerson, K.G. (2020). Coping with being cooped up: Social distancing during COVID-19 among 60+ in the United States. Rev Panam Salud Publica, 44. https://doi.org/10.26633/RPSP.2020.81

Evans, S.C., \& Bray, J. (2016). Best practice for providing social care and support to people living with concurrent sight loss and dementia: Professional perspectives. Working with Older People, 20 (2), 8693. https://doi.org/10.1108/WWOP-11-2015-0028

Fahed, M., Barron, G.C., \& Steffens, D.C. (2020). Ethical and logistical considerations of caring for older adults on inpatient psychiatry during the COVID-19 pandemic. The American Journal of Geriatric Psychiatry, 28, 829-834. https://doi.org/10.1016/j.jagp.2020.04.027

Frimpong, A.A. (2020). Epidemiological concept of Coronavirus (COVID-19) and measures for eradication: The perspective of a health economist. Public Policy and Administration Research, 10 (3), 61-75

Gethin - Jones, S. (2012). Outcomes and well - being part 2: A comparative longitudinal study of two models of homecare delivery and their impact upon the older person self - reported subjective well - being. A qualitative follow up study paper.Working with Older People, $16 \quad$ (2), 5260. https://doi.org/10.1108/13663661211231774

Gethin-Jones, S. (2014). Familial perceptions of the impact of outcome-focused homecare with older people experiencing dementia and living alone. Working with Older People, 18 (2), 9096. https://doi.org/10.1108/WWOP-12-2013-0031

Ghauri, P., \& Grønhaug, K. (2005). Research Methods in Business Studies: A Practical Guide (3 ${ }^{\text {rd }}$ ed.). Harlow: Financial Times Prentice Hall.

Guido, G., Pichierri, M., Rizzo, C., Chieffi, V., \& Moschis, G. (2020). Information processing by elderly consumers: A five-decade review. Journal of Services Marketing. https://doi.org/10.1108/JSM-09-20190368

Hamdan-Mansour, A., Al Shibi, A.N., Khalifeh, A.H., \& Hamdan-Mansour, L.A. (2020). Health-care workers' knowledge and management skills of psychosocial and mental health needs and priorities of individuals with COVID-19. Mental Health and Social Inclusion, 24 (3),135-144. https://doi.org/10.1108/MHSI-04-20200022

Hwang, J., Kim, J.H., Park, J.S., Chang, M.C., \& Park, D. (2020). Neurological diseases as mortality predictive factors for patients with COVID-19: A retrospective cohort study. Neurology Science, 8, 1-8. https://doi.org/10.1007/s10072-020-04541-z

Lara, B., Carnes, A., Dakterzada, F., Benitez, I., \& Piñol-Ripoll G. (2020). Neuropsychiatric symptoms and quality of life in Spanish Alzheimer's disease patients during COVID-19 lockdown. European Journal of Neurolology, 27, 1744-1747. https://doi.org/10.1111/ene.14339

Mahmoud-Saleh, F.I., \& Karia, N. (2020). Benchmarks for INGOs' effective responses during COVID-19 pandemic. Benchmarking: An International Journal, 27 (10), 2863-2886. https://doi.org/10.1108/BIJ-042020-0157

Manca, R., De Marco, M., \& Venneri, A. (2020). The impact of COVID-19 infection and enforced prolonged 
social isolation on neuropsychiatric symptoms in older adults with and without dementia: A Review. Frontal Psychiatry, 11, 529-540. https://doi.org/10.3389/fpsyt.2020.585540

Mullins, L.J., \& Christy, G. (2013). Management and organisational behaviour. Financial Times Publishing International.

Nagel, L. (2020). The influence of the COVID-19 pandemic on the digital transformation of work. International Journal of Sociology and Social Policy. https://doi.org/10.1108/IJSSP-07-2020-0323

Offord, C. (2020). How social isolation affects the brain. The scientist. https://www.thescientist.com/features/how-social-isolation-affects-the-brain-67701

Oliver, T., Murphy, J., \& Cox, S. (2010). She can see how much I actually do!' Talking Mats®: Helping people with dementia and family carers to discuss managing daily living. Housing, Care and Support, 13 (3), $27-$ 35. https://doi.org/10.5042/hcs.2010.0708

Omobowale, A.O., Oyelade, O.K., Omobowale, M.O., \& Falase, O.S. (2020). Contextual reflections on COVID19 and informal workers in Nigeria. International Journal of Sociology and Social Policy. https://doi.org/10.1108/IJSSP-05-

Padala, S.P., Jendro, A.M., \& Orr, L.C. (2020). Facetime to reduce behavioral problems in a nursing home resident with Alzheimer's dementia during COVID-19. Psychiatry Research. https://doi.org/10.1016/j.psychres.2020.113028

Shrira, A., Hoffman, Y., Bodner, E., \& Palgi Y. (2020). COVID-19-related loneliness and psychiatric symptoms among older adults: The buffering role of subjective age. The American Journal of Geriatric Psychiatry. https://doi.org/10.1016/j.jagp.2020.05.018.

Singh, N., Singh, S.B., Houssein, E.H., \& Ahmad, M. (2020). COVID-19: Risk prediction through nature inspired algorithm. World Journal of Engineering, https://doi.org/10.1108/WJE-08-2020-0358

Thelwall, M., \& Thelwall, S. (2020). A thematic analysis of highly retweeted early COVID-19 tweets: Consensus, information, dissent and lockdown life. Aslib Journal of Information Management. https://doi.org/10.1108/AJIM-05-2020-0134

Vindegaard, N., \& Benros, M.E. (2020). COVID-19 pandemic and mental health consequences: Systematic review of the current evidence. Brain Behaviour Immunity, 89, 531-542. https://doi.org/10.1016/j.bbi.2020.05.048

World Health Organisation, WHO (2002). World Health Report on mental disorders treatment. International Journal of Health Care Quality Assurance, 15 (1), 15-24. https://doi.org/10.1108/ijhcqa.2002.06215aab.003

World Health Organisation, WHO (2012). WHO highlights global underinvestment in mental health care. International Journal of Health Care Quality Assurance, $25 \quad$ (2), 12. https://doi.org/10.1108/ijhcqa.2012.06225baa.002

World Health Organization. (2020). WHO Director-General's opening remarks at the media briefing on COVID19-11 March 2020. World Health Organization. 11 March 2020. Retrieved 9 June 2020.

The New York Times (2020). "Coronavirus Live Updates: Europe Prepares for Pandemic as Illness Spreads From Italy". The New York Times. 26 February 2020. Retrieved 20 May 2020.

APPENDIX: SOCIO-ECONOMIC SURVEY DATA ON IMPACT OF COVID-19 IN THE U.S.

\begin{tabular}{|c|c|c|c|c|c|c|c|c|}
\hline ECONOMY & LIFE & MENTAL & WORRY & GOVT & FINANCE & FINANCE2 & CITIZEN & HOSPITAL \\
\hline 62 & 7.3 & 27 & 65 & 39 & 6 & 31 & 33 & 74 \\
\hline 66 & 6.7 & 22 & 54 & 42 & 5.5 & 34 & 37 & 71 \\
\hline 62 & 7 & 33 & 54 & 38 & 6.2 & 41 & 40 & 72 \\
\hline 51 & 7 & 18 & 58 & 39 & 5.4 & 24 & 36 & 82 \\
\hline 61 & 7.4 & 30 & 66 & 35 & 5.7 & 34 & 28 & 73 \\
\hline 69 & 7.1 & 26 & 56 & 41 & 5.7 & 30 & 33 & 74 \\
\hline 72 & 7.3 & 25 & 62 & 44 & 5.6 & 25 & 27 & 81 \\
\hline 60 & 6.8 & 16 & 54 & 42 & 5.2 & 24 & 36 & 72 \\
\hline 60 & 6.6 & 32 & 56 & 38 & 5.2 & 30 & 39 & 80 \\
\hline 67 & 6.9 & 32 & 62 & 45 & 5.4 & 30 & 38 & 80 \\
\hline 61 & 7.2 & 27 & 70 & 42 & 5.6 & 36 & 33 & 76 \\
\hline 66 & 7 & 21 & 59 & 41 & 5.3 & 27 & 38 & 79 \\
\hline 74 & 7.3 & 30 & 64 & 41 & 5.3 & 29 & 34 & 76 \\
\hline 65 & 7.4 & 34 & 67 & 30 & 5.9 & 30 & 34 & 81 \\
\hline 66 & 6.9 & 29 & 63 & 30 & 5.6 & 30 & 34 & 82 \\
\hline 59 & 6.7 & 26 & 54 & 38 & 5.1 & 28 & 30 & 69 \\
\hline 64 & 7.3 & 29 & 63 & 33 & 5.1 & 25 & 35 & 74 \\
\hline 69 & 7 & 29 & 63 & 42 & 5 & 23 & 40 & 81 \\
\hline 73 & 7.1 & 23 & 65 & 39 & 5.8 & 29 & 40 & 76 \\
\hline
\end{tabular}




\begin{tabular}{|c|c|c|c|c|c|c|c|c|}
\hline ECONOMY & LIFE & MENTAL & WORRY & GOVT & FINANCE & FINANCE2 & CITIZEN & HOSPITAL \\
\hline 73 & 7.2 & 31 & 59 & 39 & 5.5 & 28 & 37 & 76 \\
\hline 74 & 7.2 & 26 & 57 & 39 & 5.3 & 27 & 36 & 76 \\
\hline 69 & 7.2 & 29 & 65 & 38 & 5.3 & 26 & 44 & 76 \\
\hline 69 & 7 & 28 & 57 & 46 & 6.1 & 38 & 45 & 80 \\
\hline 64 & 6.8 & 30 & 59 & 37 & 5.2 & 22 & 45 & 71 \\
\hline 67 & 7.1 & 29 & 61 & 46 & 5.5 & 30 & 41 & 82 \\
\hline 69 & 7.1 & 32 & 64 & 30 & 5.8 & 32 & 39 & 82 \\
\hline 66 & 6.8 & 25 & 56 & 25 & 5 & 24 & 28 & 79 \\
\hline 66 & 7.1 & 33 & 67 & 39 & 5.7 & 27 & 35 & 74 \\
\hline 66 & 7.4 & 32 & 62 & 32 & 5.1 & 26 & 42 & 85 \\
\hline 66 & 6.8 & 30 & 60 & 34 & 6 & 38 & 25 & 74 \\
\hline 62 & 7.3 & 27 & 65 & 39 & 6 & 31 & 33 & 74 \\
\hline 66 & 6.7 & 22 & 54 & 42 & 5.5 & 34 & 37 & 71 \\
\hline 62 & 7 & 33 & 54 & 38 & 6.2 & 41 & 40 & 72 \\
\hline 51 & 7 & 18 & 58 & 39 & 5.4 & 24 & 36 & 82 \\
\hline 61 & 7.4 & 30 & 66 & 35 & 5.7 & 34 & 28 & 73 \\
\hline 69 & 7.1 & 26 & 56 & 41 & 5.7 & 30 & 33 & 74 \\
\hline 72 & 7.3 & 25 & 62 & 44 & 5.6 & 25 & 27 & 81 \\
\hline 60 & 6.8 & 16 & 54 & 42 & 5.2 & 24 & 36 & 72 \\
\hline 60 & 6.6 & 32 & 56 & 38 & 5.2 & 30 & 39 & 80 \\
\hline 67 & 6.9 & 32 & 62 & 45 & 5.4 & 30 & 38 & 80 \\
\hline 61 & 7.2 & 27 & 70 & 42 & 5.6 & 36 & 33 & 76 \\
\hline 66 & 7 & 21 & 59 & 41 & 5.3 & 27 & 38 & 79 \\
\hline 74 & 7.3 & 30 & 64 & 41 & 5.3 & 29 & 34 & 76 \\
\hline 65 & 7.4 & 34 & 67 & 30 & 5.9 & 30 & 34 & 81 \\
\hline 66 & 6.9 & 29 & 63 & 30 & 5.6 & 30 & 34 & 82 \\
\hline 59 & 6.7 & 26 & 54 & 38 & 5.1 & 28 & 30 & 69 \\
\hline 64 & 7.3 & 29 & 63 & 33 & 5.1 & 25 & 35 & 74 \\
\hline 69 & 7 & 29 & 63 & 42 & 5 & 23 & 40 & 81 \\
\hline 73 & 7.1 & 23 & 65 & 39 & 5.8 & 29 & 40 & 76 \\
\hline 73 & 7.2 & 31 & 59 & 39 & 5.5 & 28 & 37 & 76 \\
\hline 74 & 7.2 & 26 & 57 & 39 & 5.3 & 27 & 36 & 76 \\
\hline 69 & 7.2 & 29 & 65 & 38 & 5.3 & 26 & 44 & 76 \\
\hline 69 & 7 & 28 & 57 & 46 & 6.1 & 38 & 45 & 80 \\
\hline 64 & 6.8 & 30 & 59 & 37 & 5.2 & 22 & 45 & 71 \\
\hline 67 & 7.1 & 29 & 61 & 46 & 5.5 & 30 & 41 & 82 \\
\hline 69 & 7.1 & 32 & 64 & 30 & 5.8 & 32 & 39 & 82 \\
\hline 66 & 6.8 & 25 & 56 & 25 & 5 & 24 & 28 & 79 \\
\hline 66 & 7.1 & 33 & 67 & 39 & 5.7 & 27 & 35 & 74 \\
\hline 66 & 7.4 & 32 & 62 & 32 & 5.1 & 26 & 42 & 85 \\
\hline 66 & 6.8 & 30 & 60 & 34 & 6 & 38 & 25 & 74 \\
\hline
\end{tabular}

